\title{
Comparison of The Performance Levels of US Female Professional Golf Players
}

\author{
Eun-Kyung Kim ${ }^{\mathrm{a}}$ \& Jin-Seok Chae ${ }^{\mathrm{b}_{*}}$ \\ ${ }^{a}$ Professor, Department of Physical Education, Sahmyook University, Seoul, Korea \\ ${ }^{b}$ Academic Research Professor, Yongin University Sport Science Institute, Gyeonggi, Korea
}

\begin{abstract}
This study assessed the relative contribution of technical variables affecting birdies (Bir) and official money (OM) among the top 10 players of the Ladies Professional Golf Association. The average difference in performance variables was assessed according to prize money, country and continent, and time. Multiple regression analysis and one-way ANOVA were conducted, and a p-level less than .05 was considered statistically significant. First, putting average (PA) made the largest relative contribution to Bir and OM, followed by green in regulation (GIR). Second, players with highest prize-money earnings had significantly better drive distance (DD), drive accuracy (DA), sand saves (SS), and PA than median/lowest prize-money earners. Moreover, GIR was found to be accurate in distinguishing players' prize-money rankings. Third, Korean and Oceanian golfers had significantly better PA than American and European golfers; Korean golfers demonstrated better Bir, Par3, Par4, and Par5 than players from other countries and continents. Lastly, women golfers' performance improved in a 10-year-cycle. Particularly, DD, DA, and GIR significantly improved over each cycle, and Bir, Par3, Par4, and Par5, but not Eag, also significantly improved.
\end{abstract}

Key words: LPGA, golf performance, women's professional golf, official money

${ }^{1}$ Korean female professional golfers are the best in their category worldwide, and this is reflected in the 2020 Women's World Golf Rankings. In the Rolex Women's World Golf Rankings, 4, 8, 19, and 37 Korean players are ranked among the top 10, 20, 50, and 100 golfers, respectively-37\% of the top 100 female golfers worldwide are Koreans. Contrastingly, 22 US players, 11 EU players, 12 Japanese players, five Oceanian players, and three Chinese players are ranked among the top 100.

Submitted : 2 April 2021

Revised : 10 June 2021

Accepted : 21 June 2021

Correspondence : chejinseok@hanmail.net
These figures demonstrate the high performance quality of Korean female professional golfers. Performance refers to athleticism and skills. In other words, indicators such as stamina to move fiercely without resting during the game, endurance, and muscle strength and quickness to perform high-level skills safely have a narrow meaning. Broadly , "performance" refers to not only athletic and technical abilities, but also game management (Chae \& Eom, 2010). Another indicator of their performance is the prize money, which is divided into: (i) career money earned over the entire career, and (ii) official money earned during the current year. The prize money is an 
outcome of the season and reflects the player's performance, which, in golf, includes not only the average number of strokes and number of wins (Chae \& Park, 2017), but also the number of times a player finished in the top 10 (Dorsel \& Rotunda, 2001). Moreover, evaluating performance according to the player's prize-money earning (top, median, lowest), country and continent (Korea, America [the US, Canada, and South America], Europe, and OceaniAsiAf ), and time (2000, 2010, and 2020) allows a comprehensive analysis regardless of time and space. Such assessment of differences according to performance variables is appropriate for studies aiming to evaluate the importance of changes in time, the importance of affiliation, and individual economic feasibility.

Historically, changes in the national prize-money leader of the Ladies Professional Golf Association (LPGA) were predicted when UK's Laura Davies became the prize-money leader in 1994 . Thereafter, no player from the US became the prize-money leader until 2014, when Stacy Lewis topped that list. Sweden's Annika Sorenstam won three championships during 1995 and was the prize-money leader for 7 of the 10 years between 1995 and 2005-Karrie Webb from Australia lead for the remaining 3 years. The first Korean player to be placed at a high rank among prize-money leaders was Se-ri Park in 1998-the first year that she competed in professional golf tours. She became the only Korean player-with four wins- to finish second in the prize-money leaderboard after winning \$872,170 in 27 tournaments. During her first year of tour, she won the LPGA Championship and the US Women's Open Championship, receiving the Rookie of the Year award (Im \& Yoo, 2015). The following year, she placed third on the prize-money leaderboard, with Mi-hyeon Kim being placed eighth $(\$ 584,246)$.

In 2000, Mi-hyeon Kim was placed seventh and Se-ri Park 12th on the prize-money leaderboard. In 2001, 2002, and 2003, Se-ri Park was at her peak, winning the second-highest prize-money in the world for 3 consecutive years. In particular, in 2003,
Korean female professional golfers were placed second, third, and fourth on the prize-money leaderboard. From 2004 to 2008, her performance took a downturn, with other Korean players climbing up the leaderboard. In 2009 and 2010, Ji-ae Shin and Na-yeon Choi, respectively were placed first on the prize-money leaderboard. Ever since, the number of Korean female professional golfers has increased. The year 2005 was the last of Annika Sorenstam's best years, when she bagged 10 wins in the LPGA. From 2006 to 2008, Lorena Ochoa from Mexico won most championships and stayed at the top of the prize-money leaderboard. Thereafter, in 2009 and 2010, Ji-ae Shin and Na-yeon Choi became the first Koreans to top the prize-money leaderboard. In 2011, Yani Tseng became the first non-Korean Asian player to win the prize-money leader award. In 2012 and 2013, In-bi Park ranked first on the prize-money leaderboard, with In-ji Jeon, Se-young Kim, Ha-na Jang, Hee-young Yang, So-yeon Yoo, Mi-rim Kim, Hyo-ju Kim, and Mi-jeong Huh ranking among the top 20 on the prize-money leaderboard until October 2018-constituting $40 \%$ of this coveted grouping-reflecting the high performance quality of Korean female professional golfers. For the past 20 years, non-US players have been ranking first on the prize-money leaderboard-after 1993, it was only in 2014 that the US's Stacy Lewis become the prize-money leader (Jung, 2008). In 2015, Lydia Ko-a Korean-born professional golfer from New Zealand-ranked first on the prize-money leaderboard, and in 2016 and 2018, Ariya Jutanugarn from Thailand became the prize-money leader. In 2017 Seong-hyun Park, and in 2019 and 2020 Jin-young Gho became the prize-money leaders, thereby further raising the status of Korean women's golf (www.uslpga.kr, 2021).

The SCI and foreign studies related to golf performance have mainly conducted descriptive statistical analysis, correlation analysis, regression analysis, discriminant analysis, and artificial neural network analysis using 
Table 1. Classification of research variables $(n=600)$

\begin{tabular}{|c|c|c|c|c|}
\hline Year & Group variable & Technical variable (TV) & $\begin{array}{c}\text { Technical outcome variable } \\
\text { (TOV) }\end{array}$ & $\begin{array}{c}\text { Seasonal outcome variable } \\
\text { (SOV) }\end{array}$ \\
\hline 1995's & Top first-30th & \multirow{7}{*}{$\begin{array}{l}\text { DD: driving distance } \\
\text { DA: driving accuracy } \\
\text { GIR: green in regulation } \\
\text { SS: sand saves } \\
\text { PA: putting average }\end{array}$} & \multirow{4}{*}{$\begin{array}{l}\text { 1. Par3 scoring average (Par3) } \\
\text { 2. Par4 scoring average (Par4) } \\
\text { 3. Par5 scoring average (Par5) } \\
\text { 4. Birdies (Bir) }\end{array}$} & \multirow{7}{*}{$\begin{array}{l}\text { 1. Official money (OM) } \\
\text { 2. Scoring average (SA) } \\
\text { 3. Top } 10 \text { finishes } \%(\mathrm{~T} 10 \mathrm{~F})\end{array}$} \\
\hline 2000's & Median 31st-60th & & & \\
\hline 2005's & Lowest 61st-100th & & & \\
\hline 2010's & Korea & & & \\
\hline 2015's & America & & 5. Eagles (Eag) & \\
\hline 2020's & Europe & & & \\
\hline & Oceania, Asia, and & & & \\
\hline
\end{tabular}

continuous data. However, few studies have analyzed the top-ranking female golfers' performance using categorical or group variables and differences in performance by country and time (Davidson \& Templin, 1986; Belkin, Gansneder, Pickens, Rotella, \& Striegel, 1994; Engelhardt, 1997; Alexander \& Kern, 2005; Shmanske, 2008; Watkins, 2008; Wiseman \& Chatterjee, 2006; Chae, Park, \& So, 2018, 2021). In Korea, most studies used data from the Professional Golfers' Association (PGA) and LPGA, mainly focused on determinants of performance, direct performance variables that affect the winning of the championship, and differences in technical factors according to performance (Son, 2010, 2012; Kim, Choi, Kim, \& Lee, 2012; Kim \& Jo, 2013; Lee \& Lee, 2013; Kim, 2010, 2016, 2019; Park \& Chae, 2016, 2018, 2019, 2020). Contrastingly, there is a lack of academic analysis of performance using high-ranking categories or group variables.

In individual sports, the performance of top players must be analyzed to assess their common and different performance variables. Identifying the winning factors is expected to help the players compete at higher levels. Therefore, this study first assessed the relative contribution of technical variables that affect prize ranking in the top 10 LPGA players, so as to assess their relative importance. Thereafter, the average difference in performance variables was investigated according to the prize-money level (top, median, and lowest), country and continent (Korea, the US, Europe, Oceania, and Africa) and time (2000, 2010, and 2020) in players who are ranked top 100 in prize-money earnings.

\section{Methods}

\section{Research Subject}

The average data for an annual tournament in 1995, 2000, 2005, 2010, 2015, and 2020 announced through the LPGA website were used in this study, and the performance of players ranked among the top 10 or top 100 for prize-money earnings for each season was analyzed. Performance variables (13) and group study variables (3) are shown in Table 1. For a relative contribution of technical variables of top players, data of players ranked among the top 10 on the prize-money leaderboard were used, and data of 60 players over 6 years were analyzed. This is the reason that the media hails as top players those who rank among the top 10 on the prize-money leaderboard, and Top 10 Finishes \% (T10F\%) is provided as the official statistical data by the LPGA.

The study was limited to those among the top 100 on the prize-money leaderboard, given that most of the championship leaders belonged to this list. Annual average data for each season were used. Data on performance variables of 600 players for a 6 years (100 players per year) were analyzed. The mean age of the

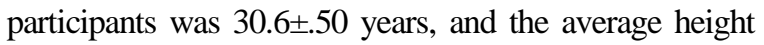
was $168.2 \pm .46 \mathrm{~cm}$.

\section{Definition of Measurement Variables}

The measurement variables used in this study were derived from LPGA championships. In the multiple 
regression analysis, independent variables (technical variables) and dependent variables (season outcome variable: official money [OM]) were used as continuous variables. In the analysis of variance, independent variables (group variables) were treated as discrete variables, and dependent variables (performance variables) were treated as continuous variables. As shown in Table 1, the one-way ANOVA was conducted using group variables as independent variables (prize level, country or continent, time) and performance variables (technical variables, technical outcome variables, and season outcome variables), which are continuous variables, as dependent variables. In the ANOVA, independent variables were divided into three groups according to the research purpose. First, those among the top 100 on the prize-money leaderboard were divided into the top (rank 1-30), median (31-60), and lowest (61-100) brackets with 180 players in the top bracket, 180 in the median, and 240 in the lowest bracket for the 6-year period (1995, 2000, 2005, 2010, 2015, 2020). Then, the players were divided by country and continent: 87 from Korea, and 323, 110, and 80 from America (the US, Canada, and South America), Europe, and OceaniAsiAf (Oceania, Asia, and Africa), respectively. Third, 10-year cycle data were used to analyze data between 2000 and 2020. Thus, data of 100 players for each of 2000, 2010, and 2020 were analyzed (Table 2).

\section{Research Issues}

The research question is presented in the following four ways:

Table 2. Group variable definition a. Do you know the relative importance of the technical parameters for the Top 10 player prize?

b. Is there a difference in the average of the performance variables according to the prize level?

c. What is the average difference in performance variables according to national level?

d. What is the average difference in performance variables over a 10 -year cycle?

\section{Data Processing Method}

First, performance variables of the top 100 players on the prize-money leaderboard for 1995, 2000, 2005, 2010, 2015, and 2020 announced on the LPGA website were organized on an Excel sheet. Multiple regression analysis and the ANOVA were performed using the SPSS 23.0 statistical program. Only the data of the top 10 players were used in the multiple regression analysis, and prize money or Bir was used as the dependent variable. Drive distance (DD), drive accuracy (DA), green in regulation (GIR), sand saves (SS), and putting average (PA) were directly entered as independent variables for analysis to calculate the standardized regression coefficient. This was to evaluate the relative contribution of descriptive variables, which are independent variables. Thereafter, the top 100 players in the official money rankings were selected for each year. This was because $99 \%$ of the championships were won by players in the top 100 rankings, and $91.2 \%$ of the winners were ranked in the top bracket of the

\begin{tabular}{|c|c|c|c|c|c|}
\hline \multicolumn{2}{|l|}{ Prize grades } & \multicolumn{2}{|l|}{ By country and continent } & \multicolumn{2}{|c|}{ By time } \\
\hline 1. Top & & 1. Republic of Korea & $\mathrm{n}=87$ & & \\
\hline $\begin{array}{l}\text { Prize-money ranking } \\
\text { (1st 30th) }\end{array}$ & $\mathrm{n}=180$ & $\begin{array}{c}\text { 2. America } \\
\text { (USA/Canada/Mexico/Peru/Brazil/Colombia/Paraguay/Chile) }\end{array}$ & $\mathrm{n}=323$ & 1. 2000 's & $\mathrm{n}=100$ \\
\hline 2. Median & & 3. Europe & & & \\
\hline $\begin{array}{l}\text { Prize-money ranking } \\
\text { (31st 60th) }\end{array}$ & $\mathrm{n}=180$ & $\begin{array}{c}\text { (UK/France/Germany/Italy/Denmark/Finland/Norway/ } \\
\text { Netherlands/Spain) }\end{array}$ & $\mathrm{n}=110$ & 2. 2010 's & $\mathrm{n}=100$ \\
\hline 3. Lowest & & 4. OceaniaAsiaAfrica & & & \\
\hline $\begin{array}{l}\text { Prize-money ranking } \\
\text { (61st 100th) }\end{array}$ & $\mathrm{n}=240$ & $\begin{array}{c}\text { (Australia/NewZealand/Japan/Thailand/Taiwan/China/ } \\
\text { Philippines/Malaysia/South Africa) }\end{array}$ & $\mathrm{n}=80$ & 3. $2020 \mathrm{~s}$ & $\mathrm{n}=100$ \\
\hline Sum total & & & $\mathrm{n}=600$ & & $n=300$ \\
\hline
\end{tabular}


Table 3. Research variable technical statistics $(n=600)$

\begin{tabular}{ccccccccc}
\hline \hline \multicolumn{2}{c}{ Variable } & Range & Min & Max & Average & SD & Skewness & kurtosis \\
\hline \multirow{6}{*}{ TV } & DD & 64 & 219 & 283 & $246.4(\mathrm{Y})$ & 10.55 & .144 & .106 \\
& DA & 39.9 & 50.0 & 89.9 & $71.2(\%)$ & 6.407 & -.271 & -.103 \\
& GIR & 26.00 & 51.6 & 77.60 & $66.2(\%)$ & 4.01 & -.114 & .078 \\
& SS & 51.7 & 19.6 & 71.33 & $41.6(\%)$ & 8.52 & .215 & .485 \\
& PA & 3.91 & 28.0 & 31.91 & 30.15 & .5969 & -.201 & .437 \\
\hline \multirow{6}{*}{ TOV } & Par3 & .34 & 2.88 & 3.22 & 3.06 & .0557 & .003 & .095 \\
& Par4 & .45 & 3.90 & 4.35 & 4.10 & .058 & -1.85 & .648 \\
& Par5 & .62 & 4.45 & 5.07 & 4.81 & .080 & -.284 & .531 \\
& Bir & 3.090 & 1.97 & 5.060 & 3.041 & .4025 & .570 & .964 \\
& Eag & .210 & 0.0 & .210 & .047 & .0335 & .938 & 1.128 \\
\hline \multirow{6}{*}{ SOV } & OM & 2762970 & 37832 & 2800802 & $331354(\$)$ & 36388 & 2.912 & 11.46 \\
& SA & 5.92 & 68.69 & 74.61 & 72.3 & .9676 & -.348 & .116 \\
& Top10F\% & 90.0 & 0.0 & 90.0 & $14.72(\%)$ & 15.64 & 1.693 & 3.031 \\
\hline \hline
\end{tabular}

prize-money leaderboard between the first and the 30th place. A total of $8.77 \%$ of the winners were in the median bracket of the prize-money leaderboard between the 31st and the 60th place, and winners were rarely ranked in the lower bracket of the leaderboard between the 61st and the 100th place.

Thereafter, the one-way ANOVA was performed to answer the second, third, and fourth aims of the study. Prior to analysis, descriptive statistics were used to evaluate the error and normality of the data (Table 3). The groups of independent variables were divided by prize level (top, median, lowest), country and continent (Korea, the US, Europe, Oceania, and Africa) and time (2000, 2010, and 2020). A total of 13 performance variables (five technical variables, five technical outcome variables, and three seasonable outcome variables) were selected as dependent variables. The one-way ANOVA was performed to assess differences in the mean of the performance variables. The post-hoc analysis was performed when significant variables were observed; the Scheffe test was used for this analysis. Tamhane's T2 method was used when assumption equal variance (Levene's test) was not established. A p-level of less than .05 was considered statistically significant for all statistical tests.

\section{Results}

Four different results were obtained. First, the relative contribution of technical variables to the prize money of the top 10 players was assessed. Second, average differences in the 13 performance variables of the top 100 players on the prize-money leaderboard were assessed according to the prize level (top, median, lowest). Third, differences in the 13 performance variables of the top 100 players on the prize-money leaderboard were assessed according to country and continent (Korea, the US, Europe, Oceania, and Africa). Fourth, differences in the performance variables of the top 100 players on the prize-money leaderboard were evaluated according to the 10-year-cycle (2000, 2010, and 2020). These results are presented in Tables 4, 5, 6, and 7 in order.

Relative Importance of Technical Variables to Prize Money or Birdies

The standardized regression coefficient $(\beta)$, which can be used to assess the relative contribution of technical variables of the top 10 players on prize-money leaderboard (data of 60 players for the six-time points from 1995 to 2020), is shown in Table 4. The $\beta$ value 
indicates the relative contribution of the technical variable to the prize money. Among the technical variables, the absolute value of PA $(|-.621|)$ was the greatest, followed by GIR (.617). Additionally, only these two variables had significant effects on the prize money, which was the dependent variable. The goodness-of-fit of the regression model was satisfactory $\left(F=17.731^{* *}, p<.05\right)$. The explanatory power of variation of the technical variables (independent variable) on the prize money (dependent variable) was $62.1 \%$, and the adjusted explanatory power $\left(R^{2}\right)$ was $58.6 \%$. The relative contribution of descriptive variables to Bir was also evaluated, which is indicated by the $\beta$ value. The technical variable with the greatest contribution was PA $(|-.759|)$, followed by GIR (.720). Those technical variables that had significant effects on Bir (dependent variable) were PA, GIR, and DD. The goodness-of-fit of the regression model was satisfactory
$\left(F=32.537^{* *}, p<.01\right)$. The explanatory power of variation of the technical variables (independent variable) on Bir (dependent variable) was $75.1 \%$, and the adjusted explanatory power $\left(R^{2}\right)$ was $72.8 \%$.

\section{Average Difference in Performance Variables According to Prize-Money Ranking}

The mean differences of performance variables according to prize-money ranking, assessed using the one-way ANOVA, are shown in Table 5. DD, which is the first technical variable, was not significantly different between the median (246.1Y) and lowest (244.3Y) groups; however, DD of the top group (249.5Y) was significantly different from that of the other two groups. Fairway hit ratio, which is the DA, was not significantly different between the median (71.6\%) and top (72.5\%) groups; however, DA of the median and top groups were

Table 4. Relative contribution of technical variables to prize money $n=60$

\begin{tabular}{|c|c|c|c|c|c|c|c|}
\hline \multirow{2}{*}{ Model } & \multicolumn{2}{|c|}{ "Non-standard coefficient } & \multirow{2}{*}{$\beta$} & \multirow{2}{*}{$t$} & \multirow{2}{*}{$p$} & \multirow[b]{2}{*}{ PCC } & \multirow[b]{2}{*}{ VIF } \\
\hline & B & SE & & & & & \\
\hline $\mathrm{C}$ & 9736953.0 & 3753548.1 & & 2.594 & .012 & & \\
\hline PA & -659704.1 & 107957.9 & -.621 & -6.111 & .0001 & -.639 & 1.473 \\
\hline GIR & 111492.6 & 22646.2 & .617 & 4.923 & .0001 & .557 & 2.243 \\
\hline DD & 9817.2 & 8059.7 & .164 & 1.218 & .229 & .164 & 2.587 \\
\hline DA & 6829.2 & 11932.7 & .078 & .572 & .569 & .078 & 2.677 \\
\hline SS & 2373.3 & 5652.0 & .040 & .420 & .676 & .057 & 1.271 \\
\hline
\end{tabular}

Note: Dependent variable, official money (OM); PCC, partial correlation coefficient; SE, standard error; $\beta$, Standardized regression coefficient; $F=17.731^{* *}, R^{2}\left(\right.$ Adjusted $\left.R^{2}\right)=.621(.586)$

Table 4-1. Relative contribution of technical variables to birdies

\begin{tabular}{|c|c|c|c|c|c|c|c|}
\hline \multirow{2}{*}{ Model } & \multicolumn{2}{|c|}{ Non-standard coefficient } & \multirow{2}{*}{$\beta$} & \multirow{2}{*}{$t$} & \multirow{2}{*}{$p$} & \multirow[b]{2}{*}{ PCC } & \multirow[b]{2}{*}{ VIF } \\
\hline & B & SE & & & & & \\
\hline $\mathrm{C}$ & 12.922 & 2.204 & & 5.864 & .0001 & & \\
\hline PA & -.583 & .063 & -.759 & -9.200 & .0001 & -.781 & 1.473 \\
\hline GIR & .094 & .013 & .720 & 7.077 & .0001 & .694 & 2.243 \\
\hline DD & .010 & .005 & .221 & 2.020 & .048 & .265 & 2.587 \\
\hline DA & -.012 & .007 & -.194 & -1.749 & .086 & -.231 & 2.677 \\
\hline SS & -.002 & .003 & -.055 & -.724 & .472 & -.098 & 1.271 \\
\hline
\end{tabular}

Note: Dependent variable, birdies (Bir); PCC, partial correlation coefficient; SE, standard error; $\beta$, Standardized regression coefficient; $F=32.537^{* *}, R^{2}\left(\right.$ Adjusted $\left.R^{2}\right)=.751(.728)$ 
significantly different from that of the lowest group (69.9\%). This finding suggests that the top and median groups have better DA than the lowest group. GIR was significantly different in the order of the lowest group (63.7\%) < median group (66.5\%) < top group (69.3\%). SS and PA were not significantly different between the median and lowest groups; however, SS and PA of the top group were significantly different from that of the median and lowest groups. Technical outcome variables including Bir, Par3, Par4, and Par5 were significantly different between the top, median, and lowest groups. However, Eag, which was not significantly different between the median and lowest groups, was significantly different between the top group and the median and lowest groups. Lastly, seasonal outcome variables including OM, Scoring Average (SA), and Top10F\% were significantly different between the three groups. The Post-hoc analysis demonstrated significant differences in seasonal outcome variables between the top and median groups and between the median and lowest groups.

Table 5. Average difference of performance variables according to performance level

\begin{tabular}{|c|c|c|c|c|c|c|c|c|c|c|c|c|c|}
\hline \multirow{2}{*}{\multicolumn{2}{|c|}{ Performance }} & \multirow{3}{*}{$\begin{array}{c}\text { variable } \\
\text { BG }\end{array}$} & \multirow{2}{*}{\multicolumn{2}{|c|}{$\begin{array}{c}\text { Tор } \\
\mathrm{M} \pm(\mathrm{SD})\end{array}$}} & \multirow{2}{*}{\multicolumn{2}{|c|}{$\begin{array}{c}\text { Median } \\
\mathrm{M} \pm(\mathrm{SD})\end{array}$}} & \multirow{2}{*}{\multicolumn{2}{|c|}{$\begin{array}{c}\text { Lower Rank } \\
\mathrm{M} \pm(\mathrm{SD})\end{array}$}} & \multirow{2}{*}{ MS } & \multirow{2}{*}{$d f$} & \multirow{2}{*}{$F$} & \multirow{2}{*}{$p$} & \multirow{2}{*}{$\begin{array}{c}\text { Post } \\
\text { Analysis }\end{array}$} \\
\hline & & & & & & & & & & & & & \\
\hline \multirow{10}{*}{ TV } & \multirow{2}{*}{$\mathrm{DD}$} & & \multirow{2}{*}{249.5} & \multirow{2}{*}{10.1} & \multirow{2}{*}{246.1} & \multirow{2}{*}{10.2} & \multirow{2}{*}{244.3} & \multirow{2}{*}{10.6} & 1399.8 & 2 & \multirow{2}{*}{13.2} & \multirow{2}{*}{.001} & \multirow{2}{*}{$\mathrm{L}, \mathrm{M}<\mathrm{T}$} \\
\hline & & WG & & & & & & & 106.0 & 597 & & & \\
\hline & \multirow{2}{*}{ DA } & BG & \multirow{2}{*}{72.5} & \multirow{2}{*}{6.3} & \multirow{2}{*}{71.6} & \multirow{2}{*}{6.1} & \multirow{2}{*}{69.9} & \multirow{2}{*}{6.5} & 359.7 & 2 & 007 & 0001 & $\mathrm{I}<\mathrm{MT}$ \\
\hline & & WG & & & & & & & 39.9 & 597 & 9.01 & .0001 & $L$ \\
\hline & GIR & BG & 69.3 & 3.2 & 66.5 & 3.0 & 63.7 & 3.5 & 1613.3 & 2 & 150.3 & .0001 & $\mathrm{~L}<\mathrm{M}<\mathrm{T}$ \\
\hline & & WG & & & & & & & 10.7 & 597 & & & \\
\hline & SS & BG & 43.8 & 8.9 & 41.1 & 7.9 & 40.4 & 84 & 636.6 & 2 & 8.99 & 0001 & $\mathrm{~L} M<\mathrm{T}$ \\
\hline & & WG & & & & & & & 70.8 & 597 & 0.37 & .0001 & $L, 1 V I$ \\
\hline & PA & BG & 300 & 06 & 302 & 06 & 303 & 06 & 5.2 & 2 & 154 & 0001 & $\mathrm{I} M<\mathrm{T}$ \\
\hline & & WG & & & & & & & 0.3 & 597 & 10.4 & .0001 & L, 1 IVI 1 \\
\hline & Rir & BG & 340 & 030 & 302 & הר & 70 & 077 & 19.2 & 2 & 1965 & 0001 & $\mathrm{I}<\mathrm{M}<\mathrm{T}$ \\
\hline & & WG & & & & & & & .098 & 597 & 100.6 & .0001 & -1 \\
\hline & Få & BG & 006 & 004 & 0.05 & $0 \Omega 3$ & 004 & 003 & .015 & 2 & 127 & O००1 & \\
\hline & Edg & WG & 0.00 & 0.04 & 0.05 & 0.03 & 0.04 & 0.03 & .001 & 597 & 13.1 & .0001 & $L, I V$ \\
\hline TOV & P3 & BG & 3.02 & 0.05 & 3.06 & 0.05 & 3.09 & 0.05 & .238 & 2 & 1034 & 0001 & $\mathrm{I}<$ \\
\hline & & WG & & & & & & & .002 & 597 & 100.4 & .0001 & $5=181<1$ \\
\hline & P4 & BG & 4.05 & 0.05 & 4.09 & 0.09 & 4.15 & 0.04 & .481 & 2 & 134.7 & .0001 & $\mathrm{~L}<\mathrm{M}<\mathrm{T}$ \\
\hline & & WG & & & & & & & .004 & 597 & & & \\
\hline & $\mathrm{p} 5$ & BG & 476 & ( 07 & 481 & 006 & 486 & 007 & .548 & 2 & 1150 & 0001 & $\mathrm{I}<\mathrm{M}<\mathrm{T}$ \\
\hline & 10 & WG & 4.70 & 0.01 & 4.01 & 0.00 & 4.00 & 0.07 & .005 & 597 & 110.0 & .0001 & $5<1 \sqrt{1}-1$ \\
\hline & $\mathrm{OM}$ & BG & 711836 & 458635 & 253486 & 94273 & 104394 & 48554 & 19756037137525 & 2 & 963 & OO०1 & $\leq T$ \\
\hline & OIVI & WG & $/ 11836$ & 458635 & 253486 & $942 \angle 3$ & 104394 & 48554 & 66674305905 & 597 & 290.3 & .0001 & $1<1 \mathrm{M}<1$ \\
\hline SOV & SA & BG & 71.3 & 0.8 & 72.3 & 0.6 & 73.0 & 07 & 142.674 & 2 & 3089 & 0001 & $\mathrm{~L}<\mathrm{M}<\mathrm{T}$ \\
\hline & & WG & & & & & & & .462 & 597 & & & \\
\hline & $\mathrm{T} 10 \mathrm{~F}$ & BG & 31.8 & 17.0 & 11.7 & 6.9 & 4.1 & 4.6 & 40594.055 & 2 & 370.2 & .0001 & $\mathrm{~L}<\mathrm{M}<\mathrm{T}$ \\
\hline & & WG & & & & & & & 109.667 & 597 & & & \\
\hline
\end{tabular}

Note: BG, between groups; WG, within the group; T=top (n:180); M=median (n:180); L=lower rank (N:240) 
Average Difference of Performance Variables According to National Classification

The mean differences of the 13 performance variables according to country and continent are shown in Table 6. Among the first five technical variables, DA and GIR were not significantly different according to country classification. DD, SS, and PA were significantly different, and the post-hoc analysis showed that DD of Korean players was not significantly different from that of players from other countries or continents. However, players from Europe (248.8Y) and OceaniAsiAf (249.5Y) had significantly higher DD than players from America (244.7). Korean players had better SS (45.4\%) in BG than other players from different countries and continents. PA was significantly higher in players from Korea and OceaniAsiAf than in those from Europe and America. Among the technical outcome variables, only Eag of Korean players was not significantly different from that of players from America, Europe, or

Table 6. Average difference according to country classification ( $K: n=87, A: n=180, E: n=110,0: n=80$ )

\begin{tabular}{|c|c|c|c|c|c|c|c|c|c|c|c|c|c|c|}
\hline \multirow{2}{*}{\multicolumn{3}{|c|}{$\begin{array}{l}\text { Performance } \\
\text { variable }\end{array}$}} & \multirow{2}{*}{\multicolumn{2}{|c|}{$\begin{array}{l}\text { Korea } \\
\mathrm{M} \pm \mathrm{SD}\end{array}$}} & \multirow{2}{*}{\multicolumn{2}{|c|}{$\begin{array}{c}\text { America } \\
\mathrm{M} \pm \mathrm{SD}\end{array}$}} & \multirow{2}{*}{\multicolumn{2}{|c|}{$\begin{array}{l}\text { Europe } \\
\mathrm{M} \pm \mathrm{SD}\end{array}$}} & \multirow{2}{*}{\multicolumn{2}{|c|}{$\begin{array}{c}\text { OceaniAsiAf } \\
\mathrm{M} \pm \mathrm{SD}\end{array}$}} & \multirow{2}{*}{$d f$} & \multirow{2}{*}{$F$} & \multirow{2}{*}{$p$} & \multirow{2}{*}{ Post Analysis } \\
\hline & & & & & & & & & & & & & & \\
\hline \multirow{5}{*}{ TV } & $\mathrm{DD}$ & $\begin{array}{l}\text { BG } \\
\text { WG }\end{array}$ & 246.7 & 7.7 & 244.7 & 10.8 & 248.8 & 10.7 & 249.5 & 9.9 & $\begin{array}{c}3 \\
596\end{array}$ & 7.26 & .001 & $\mathrm{~A}<\mathrm{E}, \mathrm{O}$ \\
\hline & DA & $\begin{array}{l}\text { BG } \\
\text { WG }\end{array}$ & 71.9 & 7.4 & 71.4 & 6.1 & 70.6 & 6.3 & 70.9 & 6.6 & $\begin{array}{c}3 \\
596\end{array}$ & 0.92 & .43 & $x$ \\
\hline & GIR & $\begin{array}{l}\text { BG } \\
\text { WG }\end{array}$ & 66.8 & 4.4 & 66.0 & 3.8 & 66.4 & 4.2 & 66.4 & 3.8 & $\begin{array}{c}3 \\
596\end{array}$ & 1.09 & .44 & $x$ \\
\hline & SS & $\begin{array}{l}\text { BG } \\
\text { WG }\end{array}$ & 45.4 & 9.8 & 40.6 & 7.9 & 40.7 & 8.4 & 44.2 & 8.3 & $\begin{array}{c}3 \\
596\end{array}$ & 18.9 & .01 & $\begin{array}{c}\mathrm{A}, \mathrm{E}<\mathrm{K} \\
\mathrm{A}<\mathrm{O}\end{array}$ \\
\hline & $\mathrm{PA}$ & $\begin{array}{l}\text { BG } \\
\text { WG }\end{array}$ & 29.8 & 0.691 & 30.248 & 0.5446 & 30.243 & 0.5722 & 30.002 & 0.5334 & $\begin{array}{c}3 \\
596\end{array}$ & 9.16 & .001 & $\mathrm{~A}, \mathrm{E}<\mathrm{O}, \mathrm{K}$ \\
\hline \multirow{5}{*}{ TOV } & Bir & $\begin{array}{l}\text { BG } \\
\text { WG }\end{array}$ & 3.21 & 0.5 & 2.96 & 0.4 & 3.09 & 0.4 & 3.13 & 0.4 & $\begin{array}{c}3 \\
596\end{array}$ & 12.4 & .001 & $\mathrm{~A}<\mathrm{E}, \mathrm{O}, \mathrm{K}$ \\
\hline & Eag & $\begin{array}{l}\text { BG } \\
\text { WG }\end{array}$ & .05 & .03 & .04 & .03 & .055 & .037 & .058 & .039 & $\begin{array}{c}3 \\
596\end{array}$ & 7.93 & .001 & $\mathrm{~A}<\mathrm{E}, \mathrm{O}$ \\
\hline & P3 & $\begin{array}{l}\text { BG } \\
\text { WG }\end{array}$ & 3.041 & 0.058 & 3.062 & 0.053 & 3.063 & 0.056 & 3.058 & 0.060 & $\begin{array}{c}3 \\
596\end{array}$ & 3.66 & .01 & $\mathrm{~A}<\mathrm{K}$ \\
\hline & P4 & $\begin{array}{l}\text { BG } \\
\text { WG }\end{array}$ & 4.068 & 0.129 & 4.11 & 0.06 & 4.11 & 0.06 & 4.1 & 0.05 & $\begin{array}{c}3 \\
596\end{array}$ & 8.46 & .001 & $\mathrm{~A}<\mathrm{K}$ \\
\hline & P5 & $\begin{array}{l}\text { BG } \\
\text { WG }\end{array}$ & 4.78 & 0.097 & 4.83 & 0.07 & 4.81 & 0.08 & 4.777 & 0.08 & $\begin{array}{c}3 \\
596\end{array}$ & 11.3 & .001 & $\mathrm{~A}, \mathrm{E}<\mathrm{K}, \mathrm{O}$ \\
\hline \multirow{3}{*}{ SOV } & $\mathrm{OM}$ & $\begin{array}{l}\text { BG } \\
\text { WG }\end{array}$ & 521435 & 508312 & 276190 & 278522 & 308013 & 394011 & 379458 & 330543 & $\begin{array}{c}3 \\
596\end{array}$ & 11.6 & .001 & $\mathrm{~A}, \mathrm{E}<\mathrm{K}$ \\
\hline & SA & $\begin{array}{l}\text { BG } \\
\text { WG }\end{array}$ & 71.9 & 1.1 & 72.4 & .9 & 72.3 & 1.0 & 72.1 & 0.9 & $\begin{array}{c}3 \\
596\end{array}$ & 8.75 & .001 & A, $\mathrm{E}<\mathrm{K}$ \\
\hline & $\mathrm{T} 10 \mathrm{~F}$ & $\begin{array}{l}\text { BG } \\
\text { WG }\end{array}$ & 19.8 & 21.5 & 13.5 & 13.4 & 14.8 & 15.7 & 14.3 & 15.6 & $\begin{array}{c}3 \\
596\end{array}$ & 3.82 & .01 & $\mathrm{~A}<\mathrm{K}$ \\
\hline
\end{tabular}

Note: BG, between groups; WG, within the group; K, Korea; A, America; E, Europe; O, OceaniaAsiAfrica 
OceaniAsiAf. Bir was greater in players from Europe (3.09), OceaniAsiAf (3.13), and Korea (3.21) than in players from America. Par3 and Par 4 were significantly different between Korean and American players; however, Par 5 was significantly higher in players from Korea and OceaniAsiAf than in players from America and Europe. Seasonal outcome variables included OM, SA and Top $10 \mathrm{~F} \%$. Korean players showed significantly higher OM, SA, and Top10F\% than American and
European players. In particular, players from Korea had significantly higher OM than American and European players. Moreover, SA was significantly lower in Korean players than in those from America and Europe.

Average Difference in Performance Variables According to the 10-year Cycle

Table 7 shows the average difference in performance variables according to the 10 -year-cycle. DD, DA and

Table 7. Average difference over a 10-year cycle

\begin{tabular}{|c|c|c|c|c|c|c|c|c|c|c|c|c|c|}
\hline \multirow{2}{*}{\multicolumn{3}{|c|}{$\begin{array}{c}\text { Performance } \\
\text { variable }\end{array}$}} & \multirow{2}{*}{\multicolumn{2}{|c|}{$\begin{array}{c}\text { 2000's } \\
\mathrm{M} \pm(\mathrm{SD})\end{array}$}} & \multirow{2}{*}{\multicolumn{2}{|c|}{$\begin{array}{c}2010 ' s \\
M \pm(S D)\end{array}$}} & \multirow{2}{*}{\multicolumn{2}{|c|}{$\begin{array}{c}\text { 2020's } \\
\mathrm{M} \pm(\mathrm{SD})\end{array}$}} & \multirow{2}{*}{ MS } & \multirow{2}{*}{$d f$} & \multirow{2}{*}{$F$} & \multirow{2}{*}{$p$} & \multirow{2}{*}{$\begin{array}{c}\text { Post } \\
\text { Analysis }\end{array}$} \\
\hline & & & & & & & & & & & & & \\
\hline \multirow{10}{*}{ TV } & \multirow{2}{*}{ DD } & BG & \multirow[t]{2}{*}{242.1} & \multirow{2}{*}{8.7} & \multirow{2}{*}{248.5} & \multirow[t]{2}{*}{8.9} & \multirow{2}{*}{254.1} & \multirow[t]{2}{*}{9.4} & 3633 & 2 & \multirow[t]{2}{*}{44.5} & \multirow{2}{*}{.0001} & \multirow{2}{*}{$20<21<22$} \\
\hline & & WG & & & & & & & 81.6 & 297 & & & \\
\hline & \multirow{2}{*}{ DA } & BG & \multirow{2}{*}{70.1} & \multirow{2}{*}{5.5} & \multirow{2}{*}{66.7} & \multirow{2}{*}{6.1} & \multirow{2}{*}{74.0} & \multirow{2}{*}{5.6} & 1344 & 2 & \multirow{2}{*}{41.1} & O००1 & 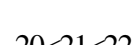 \\
\hline & & WG & & & & & & & 32.7 & 297 & & .0001 & $2 U<21<22$ \\
\hline & GIR & & 640 & 35 & 6582 & 42 & 675 & 34 & 307.7 & 2 & 223 & 0001 & $20<21<22$ \\
\hline & & WG & & & & & & & 13.8 & 297 & & .0001 & $20>21<22$ \\
\hline & SS & BG & 389 & 77 & 4031 & 73 & 481 & 867 & 2417 & 2 & 387 & 0001 & $2021<22$ \\
\hline & & WG & & & & & & & 62.4 & 297 & & & \\
\hline & PA & BG & 301 & 52 & ר० 90 & 06 & 300 & 055 & 1.16 & 2 & 366 & (2) & $20<21$ \\
\hline & & WG & & & & & & & .316 & 297 & & & \\
\hline & $\operatorname{Dir}$ & BG & 209 & 24 & 212 & 10 & 21 & 27 & .817 & 2 & 509 & ( $00 ?$ & רי גריר? \\
\hline & DIII & WG & 2.50 & .34 & 0.10 & . & 0.1 & וב & .137 & 297 & 0.90 & .003 & $20<21,22$ \\
\hline & Eag & BG & 05 & 03 & 05 & 04 & 05 & 04 & .001 & 2 & 107 & 345 & $x$ \\
\hline & & WG & & & & & & & .001 & 297 & 1.01 & & \\
\hline TOV & P3 & BG & 3.07 & 05 & 305 & 05 & 31 & 006 & .013 & 2 & 125 & 015 & רכ \\
\hline & & WG & & .00 & 0.03 & .03 & 0.1 & 0.00 & .003 & 297 & 4.25 & (1) & $20<21,22$ \\
\hline & P4 & BG & 412 & 05 & 410 & 06 & 408 & (2) & .039 & 2 & 564 & 004 & \\
\hline & & WG & & & & & & & .007 & 297 & & & \\
\hline & $\mathrm{D} 5$ & BG & 197 & 06 & 193 & 00 & 76 & 00 & .135 & 2 & 251 & $0 \cap 01$ & רכ<ו 20 \\
\hline & FJ & WG & 4.02 & .00 & 4.03 & .00 & 4.70 & 0.00 & .005 & 297 & 20.1 & .0001 & $20,21<22$ \\
\hline & & BG & & & & & & & 160105850879 & 2 & & & \\
\hline & $\mathrm{OM}$ & & 277067 & 280904 & 356983 & 413281 & 320671 & 284634 & & & 1.45 & .236 & $x$ \\
\hline & & WG & & & & & & & 110241427429 & 297 & & & \\
\hline SOV & & BG & & & & & & & 23.3 & 2 & & & \\
\hline & SA & WG & 72.5 & .78 & 72.38 & 1.0 & 71.63 & 0.82 & .773 & 297 & 30.2 & .0001 & $20,21<22$ \\
\hline & $\mathrm{T} 10 \mathrm{~F}$ & BG & 16.6 & 16 & 13.2 & 18. & 14.8 & 15.2 & 292 & 2 & 1.09 & .337 & $x$ \\
\hline & & WG & & & & & & & 267 & 297 & & & \\
\hline
\end{tabular}

Note: BG, between groups; WG, within the group; 20=2000's $(n=100) ; 21=2010$ 's $(n=100) ; 22=2020$ 's $(n=100)$ 
GIR significantly changed during the 10 years. SS was significantly different in 2020 (48.1\%) compared to 2010 (40.31\%) and 2000 (38.94\%). For technical variables, Bir was significantly higher in 2010 and 2020 than in 2000. However, Eag was not significantly different. Additionally, P3, P4, and P5 were significantly different in 2020 compared to other years. Among the three seasonal outcome variables, OM and $\mathrm{T} 10 \mathrm{~F} \%$ were not significantly different over time. In contrast, SA was significantly improved in 2020 compared to that in 2000 and 2010.

\section{Discussion}

There are four points of discussion in this study. First, among the five technical variables, only PA and GIR made a significant relative contribution to the prize money of the top 10 players. PA had the greatest relative contribution, followed by GIR. Moreover, PA also made the greatest relative contribution to Bir, followed by GIR and DD. These three factors made a significant contribution to Bir. However, this finding is opposite to the findings by Park and Chae (2017) who showed that GIR made the greatest contribution, followed by PA. In the analysis of the top 100 players on the prize-money leaderboard, GIR was the most important factor. Contrastingly, in an analysis of the top 10 players, PA made the greatest relative contribution to the prize money. This finding suggests that players must practice putting among the five technical variables, have an accurate iron shot for increased GIR, and improve DD for easier Bir. If the DD is long, the players can aim for the green with an iron shot. If players can hit the ball closer to the flagpole than their opponents can, then they have a better chance of hitting a birdie, thanks to easier putting. Moreover, an average of two putting strokes per hole on a par 72 course to maintain a par would make putting equivalent to $50 \%$ of each round.

Second, the average difference in performance variables according to prize money (top, median, lowest) was assessed. DD, SS, and PA were greater in the top group than in the median and lowest groups. This finding suggests that players need to practice and improve their PA, DD, and SS for better prize-money earnings. DA was more accurate in the top and median groups than in the lowest group. GIR was significantly different between the three groups, suggesting its accuracy in distinguish the prize-money ranking of players. Similar to our study, Choi, Choi, and Kim (2014) divided players into top, median, and lowest groups according to performance. GIR and PA were significantly different between all groups. DD was significantly different between the top/median group and the lowest group, and DA was different only between the top and median groups. SS was significantly different between the top group and median/lowest groups. Moreover, Park and Chae (2018) reported that GIR was the technical variable with the greatest effects on prize money, and Son and Lee (2013), who analyzed the effects of variables on the prize money, also showed that GIR was the most important factor for prize money. These findings are in agreement with our findings. In another study on 175 professional golfers who played in LPGA championships, Jung (2008) analyzed the correlation between the prize money earned per round and game variables. Those players with excellent putting precision and short game ability with a high GIR earned relatively large prize money. Park and Chae (2018) reported that PA had the second greatest effect on prize money after GIR. This is consistent with our finding that the F value of PA was the second largest among that of technical variables. Therefore, this finding suggests that those players who wish to earn more prize money must train more to improve their putting skills. Assessment of the average difference in technical outcome variables (Bir, Eag, Par3, Par4, and Par5) showed that Bir (the average number of birdies per round) and Par 4 (average number of strokes in Par 4) better distinguish the prize-money earnings compared to other technical outcome variables. Park and Chae (2018) showed that $80 \%$ and $56 \%$ of players with the most prize-money earning every year 
for 25 years were placed first and second for Bir and Par4, respectively, which is in agreement with our finding. Moreover, Son and Kim (2010) reported that birdies had the greatest effects on the performance of LPGA Tour players. Previous studies have investigated technical variables that affect Bir, which is an important variable for prize money. In a study of performance variables of female golfers using LPGA data, Park and Chae (2016) reported that GIR and PA among the five technical variables had the greatest relative effects on Bir. However, in our study, where we analyzed the data of the top 10 players, PA had the greatest effects on Bir, followed by GIR.

Analysis of the average difference of performance variables according to country and continent (Korea, America, Europe, and OceaniAsiAf) showed that players from Korea and OceaniAsiAf had significantly better SS and PA compared to those from other countries. Moreover, Korean players had significantly better Bir, Par3, Par4, and Par5, but not Eag, compared to players from other countries and continents. Korean golfers also showed significantly better seasonal outcome variables (OM, SA, and Top10F\%). DD, DA, GIR, and Eag were not significantly different in Korean players compared to their counterparts from other countries and continents. Park and Chae (2018) showed that between 2011 and 2017, Korean players had significantly better SS, PA, and DA but had worse DD than players from the US. Such difference between their findings and our results may be attributed to the difference in time.

Our findings further demonstrated that performance variables increased with time. First, all five technical variables significantly differed with time. In particular, DD, DA, and GIR were markedly changed over time. For technical outcome variables, Bir, and Par3, Par4, Par5, except Eag, were significantly improved over time. Contrastingly, for seasonable outcome variables, only SA was improved over time. This finding is different from that of a previous study. In a study on the performance of golfers over 5-year cycles until
2015, Chae and Park (2017) showed that DD, GIR, SR improved every 5 years, and technical outcome variables, including Bir, Par3, Par4, and Par5, but not Eag, also improved over time. Seasonable outcome variables (OM and SA) also improved. These discrepancies between our and their findings may be attributed to the selection of different years for data.

\section{Conclusion and Suggestions}

The four main conclusions of this study are as follows. First, among technical variables, PA made the largest relative contribution to the prize money of the top 10 players, followed by GIR. This finding suggests that players must practice putting and increase their GIR. This will increase the number of birdies, reducing SA and increasing prize money. Second, players who wish to rank in the top 30 for prize-money earned must improve their ADD, SS, and PA as players in the top group of prize-money earned had significantly better $\mathrm{ADD}, \mathrm{SS}$, and PA than those in the median/lowest groups. Thus, golfers aiming for top prize-money earnings should train to improve their PA, DD, and SS. Additionally, players must increase their number of Bir and perform better in Par4 than their competitors. Our finding showed that top players had significantly greater Bir and Par4 performance, which better distinguished prize-money earnings. Third, Korean golfers had significantly better SS and PA as well as Bir, Par3, Par 4, Par5 performance compared to golfers from other countries and continents. Fourth, the golfers overall showed improved performance over time. In particular, DD, DA, and GIR showed clear improvements over time, and technical outcome variables, including Bir, Par3, Par4, and Par5, but not Eag, were significantly improved. These results show that those Korean players who play or wish to play in the LPGA championship to become a top prize-money winner must prioritize PA and GIR. Those players in the past with top prize-money earnings had great Bir, which was affected by PA, GIR, and DD. The golf course of the LPGA has expanded 
compared to 20 years ago, and the fairways are narrow, such that the chance of Bir is increased when DD and DA are improved.

Therefore, those players who wish to win the championships must train to improve PA and GIR and allocate their practice times for DD, DA and SS in that order of priority.

\section{References}

Alexander, D. L., \& Kern, W. (2005). Drive for show and putt for dough? An analysis of the earnings of PGA tour golfers. Journal of Sports Economics, 6(1), 46-60.

Belkin, D. S., Gansneder, B., Pickens, M., Rotella, R. J., \& Striegel, D. (1994). Predictability and stability of Professional Golf Association tour statistics. Perceptual and Motor Skills, 78(3 Part 2), 1275-80.

Chae, J. S., \& Eom, H. J. (2010). Trend analysis of annual rankings and evaluation of relative team skill performance for Korean pro-baseball teams. Korean Journal of Sport Science, 21(1), 956-73.

Chae, J. S., \& Park, J. (2017). Five years per cycle performances according to the average of the difference between LPGA players and trend analysis. Korean Journal of Golf Studies, 11(1), 19-32.

Chae, J. S., Park, J., \& So, W. Y. (2018). Ranking prediction model using the competition record of Ladies Professional Golf Association players. Journal of Strength and Conditioning Research, 32(8), 2363-74.

Chae, J. S., Park, J., \& So, W. Y. (2021). Victory prediction of Ladies Professional Golf Association players: Influential factors and comparison of prediction models. Journal of Human Kinetics, 77, 245-59.

Choi, S. P., Choi, B. A., \& Kim, Y. H. (2014). Effects of technical factors of LPGA golfers on performance in 2012. Korean Journal of Golf Studies, 8(2), 19-30.
Davidson, J., \& Templin, T. (1986). Determinants of success among professional golfers. Research Quarterly for Exercise and Sport, 57(1), 60-67.

Dorsel, T. N., \& Rotunda, R. J. (2001). Low scores, top 10 finishes, and big money: An analysis of Professional Golf Association tour statistics and how these relate to overall performance. Perceptual and Motor Skills, 92(2), 575-85.

Engelhardt, G. M. (1997). Differences in shot-making skills among high and low money winners on the PGA tour. Perceptual and Motor Skills, 84(3Pt2), 1314.

Im, J. T., \& Yoo, D. H. (2015). History of LPGA Tour entry process of the Korean female professional golfers: Focusing on entry timing of Park Se-Ri. Korea Journal of Sport History, 20(4), 99-111.

Jung, D. H. (2008). Relation between prize (dollars) per round and the records of golfers in LPGA. Journal of Data Analysis Society, 10(1), 513-522.

Kim, S. H., \& Cho, J. H. (2013). Effectiveness of golf skills to average score using records of PGA, LPGA, KPGA, KLPGA: Multi-group path analysis. Journal of the Korean Data Information Science Society, 24(3), 543-55.

Kim, S. H., Choi, J. I., Kim, Y. G., \& Lee, J. W. (2012). Analysis of structure model for performance in PGA player: Multi-group factor analysis. Korean Journal of Golf Studies, 6(1), 97-105.

Kim, S. I. (2010). Analysis of skill factors for the improvement of golf performance in golf tour. Journal of Coaching and Development, 12(3), 103-12.

Kim, S. I. (2016). Analysis of skill factors of golf performance in LPGA tour (1993 2015). Korean Journal of Golf Studies, 10(4), 49-59.

Kim, S. I. (2019). Analysis of golf skill factors of Korean women golfers in LPGA tour. Korean Academy of Sport Science, 28(2), 1187-99.

Lee, Y. H., \& Lee, J. G. (2013). Research of winning factors that KLPGA players thought. Korean Journal of Golf Studies, 7(1), 75-83. 
LPGA. (2021). www.uslpga.kr/

Park, J., \& Chae, J. S. (2016). A study of women's golf performance variables using LPGA data. Korean Journal of Golf Studies, 10(3), 79-88.

Park, J., \& Chae, J. S. (2017). Effects of technology variables and technology output variables on the output of the season according to 10-year cycle of LPGA. Korean Society of Measurement and Evaluation for Physical Education and Sports Science, 19(3), 1-12.

Park, J., \& Chae, J. S. (2018). The effects of the LPGA's performance variables on seasonal results and the average differences and trends between continentals. Korean Society of Measurement and Evaluation for Physical Education and Sports Science, 20(4), 87-101.

Park, J., \& Chae, J. S. (2020). Technical conditions for winning Korean players playing in PGA. Korean Journal of Golf Studies, 14(3), 87-100.

Shmanske, S. (2008). Skills, performance, and earning in the tournament compensation model: Evidence from PGA tour. Journal of Sports Economics, 9(6), 644-53.

Son, W. B. (2010). The exploring appropriate time of endorsement by predicting LPGA players' tour performance factors. Korean Society for Sport Management, 15(5), 17-32.

Son, W. B. (2012). An analysis of performance factors for effective endorsement of LPGA tour players. Korean Society for Sport Management, 17(4), 31-43.

Son, W. B., \& Kim, Y. K. (2010). Exploration of game result determinant factors apply to 2008 PGA \& LPGA tour stats. Journal of Coaching Development, 12(1), 151-60.

Son, W. B., \& Lee, C. J. (2013). An exploration of tour skill factors influential to game results of LPGA players. Journal of the Korean Data Information Science Society, 24(2), 369-77.

Watkins, J. R. J. (2008). Drive for show, putt for dough: Rates of return to golf skills, events played and age on the PGA tour. Michigan Journal of Business Year, 1(1), 35-59.

Wiseman, F., \& Chatterjee, S. (2006). Comprehensive analysis of golf performance on the PGA tour: 1990-2004. Perceptual and Motor Skills, 102(1), 109-17. 